\title{
High pressure pre-treatment of Moringa oleifera seed kernels prior to aqueous enzymatic oil extraction
}

Article

Accepted Version

Creative Commons: Attribution-Noncommercial-No Derivative Works 4.0

Mat Yusoff, M. B., Gordon, M. H., Ezeh, O. and Niranjan, K. (2017) High pressure pre-treatment of Moringa oleifera seed kernels prior to aqueous enzymatic oil extraction. Innovative Food Science and Emerging Technologies, 39. pp. 129-136. ISSN 1466-8564 doi:

https://doi.org/10.1016/j.ifset.2016.11.014 Available at https://centaur.reading.ac.uk/68173/

It is advisable to refer to the publisher's version if you intend to cite from the work. See Guidance on citing.

To link to this article DOI: http://dx.doi.org/10.1016/j.ifset.2016.11.014

Publisher: Elsevier

All outputs in CentAUR are protected by Intellectual Property Rights law, including copyright law. Copyright and IPR is retained by the creators or other copyright holders. Terms and conditions for use of this material are defined in the End User Agreement. 


\section{CentAUR}

Central Archive at the University of Reading

Reading's research outputs online 


\section{High pressure pre-treatment of Moringa oleifera seed kernels prior to aqueous enzymatic oil extraction}

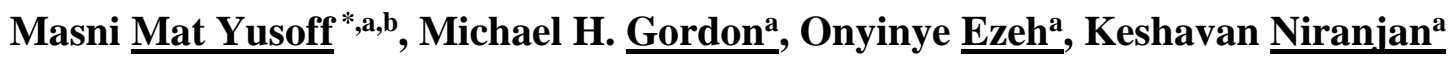

aDepartment of Food and Nutritional Sciences, University of Reading, Whiteknights, PO Box 224, Reading, RG6 6AP, United

\section{Kingdom}

${ }^{\mathrm{b}}$ Department of Food Technology, Faculty of Food Science and Technology, Universiti Putra Malaysia, 43400 Serdang, Selangor, Malaysia

*Corresponding author:

Tel. : +447450502242

$$
\text { : +60176068925 }
$$

E-mail address: m.matyusoff@pgr.reading.ac.uk

$$
\text { : masniyusoff@upm.edu.my }
$$

\section{Abstract}


High pressure processing (HPP) was applied as a pre-treatment on Moringa oleifera (MO) kernels, for the first time, prior to aqueous enzymatic extraction (AEE) of the MO oil, and the effect of this pre-treatment is reported in terms of the free oil recovery and the nature of the cream emulsions formed. The HPP pre-treatments $\left(50-250 \mathrm{MPa}, 20-60{ }^{\circ} \mathrm{C}, 10-60 \mathrm{~min}\right)$ generally resulted in higher free oil recoveries and thinner emulsion layers from ground-sieved kernels than the whole kernels. Optimization of the HPP parameters indicated linear increment in free oil recovery with increase in temperature and time, but not the pressure level. Without the pre-boiling step in the AEE process, the use of HPP pre-treatment at $50 \mathrm{MPa}$ and $60{ }^{\circ} \mathrm{C}$ for 35 min resulted in approximately $73 \%$ (w/w) free oil recovery with thinner emulsion layer than the use of AEE alone. These findings highlighted the ability of HPP in altering the MO protein structure into a form of less emulsifying functional properties, thus further de-emulsification method may not be necessary.

Keywords: Moringa oleifera, seed kernels, oil, enzyme, high pressure processing, emulsion

\section{Highlights}

- Oil recovery is not significantly affected by pressure applied

- Increase in time and temperature of high pressure application increase oil recovery

- The thickness of creamy o/w emulsion formed after extraction drops significantly 


\section{Industrial relevance}

High pressure processing (HPP) applications are increasing in the food industry. High pressure application allows the use of relatively lower temperatures in processes, in order to achieve comparable outcomes of higher temperature processing. This study explores the application of HPP on Moringa oleifera (MO) kernels prior to aqueous enzymatic extraction (AEE) of oil. In general, the main disadvantage of AEE is its lower oil recovery in comparison with solvent extraction, which is attributed to the formation of a relatively stable cream emulsion after extraction. This study shows that the thickness of the creamy emulsion can be significantly reduced, and oil recoveries improved, by subjecting the kernels to HPP prior to extraction. The improvement in recoveries did not depend strongly on the level of high pressure applied, but downstream processes for free oil separation and recovery were considerably simplified.

\section{Introduction}

Aqueous enzymatic extraction (AEE) of oil from oil-bearing materials was reviewed by Mat Yusoff et al. (2015) and Rosenthal et al. (1996). This process involves addition of selected enzymes into a mixture of oleaginous material with pre-determined amount of water at a given $\mathrm{pH}$ value, followed by incubation of the mixture at a pre-set temperature, time, and shaking speed. The added enzymes function in hydrolyzing and breaking the cotyledon cell walls of the material, thus making the structure more permeable and 
further expose the oil component. The water-soluble components diffuse into the aqueous phase, while the released oil distributes itself between two phases: i) an oil-in-water cream emulsion in the aqueous phase and ii) a superficial oil layer on top of the emulsion (Rosenthal et al.1998).

The advantages of AEE over solvent extraction were also pointed out by Rosenthal et al (1998), which include lower environmental impact and lower process costs. In the case of Moringa oleifera (MO) kernels, the use of AEE was reported by Abdulkarim et al. (2005, 2006),Latif et al. (2011), and Mat Yusoff et al. (2016) which highlighted the importance of protein hydrolysis in the MO kernels for higher free oil recovery. Further, the kernels contain in excess of 35\% protein content (w/w), and their microscopic structure indicates that the oil bodies in the cells are surrounded predominantly by protein (Mat Yusoff et al., 2016).

Abdulkarim et al. (2006) also reported that the use of protease in combination with cellulase enzymes resulted in higher oil yield than the use of protease enzyme alone. Hence, the main enzyme used in earlier studies were mainly protease and cellulase. It is noteworthy that MO oil exhibits high oxidative stability due to the presence of high levels of tocopherols which also reduce the risk of developing coronary heart disease (Zhao \& Zhang, 2013; Nguyen et al. 2011; Rahman et al., 2009; Abdulkarim et al., 2006; Noakes et al., 1996).

Despite its obvious advantages, the MO free oil recoveries resulting from AEE are significantly lower than the recoveries observed by solvent extraction, ranging between $69-73 \%$ of solvent-extracted oil recovery (Mat Yusoff et al., 2016; Latif et al., 2011; Abdulkarim et al., 2006, 2005). Mat Yusoff et al. (2016) and Latif et al. (2011) found that the MO cream emulsion formed at the end of the AEE process required further de-emulsification in order to enhance free oil recovery, which was particularly difficult because of the added emulsion stability imparted by the proteins. Formation of creamy emulsion following an AEE process was also reported in 
the case of Isatis indigocita seeds (Gai et al., 2013), bayberry kernels (Zhang et al., 2012), and soybean seeds (Lamsal and Johnson, 2007); which in the latter case, extrusion was used as a pre-treatment on soybean seeds prior to AEE of soybean oil to prevent the formation of cream emulsion.

These findings therefore suggest that free oil recoveries can be enhanced by decreasing the emulsifying capacity of the proteins, possibly by altering their structures. The alteration of protein structure may be induced by both hydrolysis and denaturation, which can be promoted by subjecting the kernels to treatments such as high pressure processing (HPP). Upon denaturation, the peptide bonds of the protein become more available or more susceptible to hydrolysis by proteolytic enzymes, besides lowering the protein solubility (Anglemier \& Montgomery, 1976). In addition, HPP also disrupts electrostatic and hydrophobic interactions in proteins (Messens et al., 1997). HPP has been used in earlier studies to enhance oil yields. For instance, Jung \& Mahfuz (2009) stated that the use of HPP at $200 \mathrm{MPa}$ and $500 \mathrm{MPa}$, followed by AEE (protease enzyme), resulted in 3.20\% and 1.30\% (w/w) higher soybean oil yield, respectively, under otherwise identical conditions. In the case of tiger nuts on the other hand, Ezeh et al. (2016) reported no significant difference in the oil yield from an AEE alone and from AEE with HPP pre-treatment at 50-700 MPa. It was reported that the parenchyma cells of the tubers exhibit cross linking of diferulic acid with arabinoxylans which contribute to its tough texture, even tougher than potatoes (Parker et al., 2000), thus the tuber's cells were not affected by the HPP pre-treatment. On the other hand, Omi et al. (1996) reported that the solubility of soybeans' protein in aqueous phase increased with pressure from 100MPa to 400MPa, and decreased thereafter. Kato et al. (2000) also reported considerable release of proteins from polished rice grains soaked in a mixture of enzyme and distilled water and treated with HPP at 100-400 MPa. 
The role of protein as an emulsifier varies greatly as reported by Denda \& Hayashi (1992), Kajiyama et al. (1995), Galazka et al. (2000), Molina et al. (2001), and Chapleau \& de Lamballerie-Anton (2003). Additionally, the factors affecting protein denaturation and hydrolysis may or may not affect the role of the protein as an emulsifier. Based on these theories and outcomes of earlier studies, it appears that a combination of protein denaturation caused by HPP, followed by protein hydrolysis employing AEE may

significantly influence MO free oil recovery. This study aims to investigate this hypothesis as a novel application of HPP. To the best of our knowledge, there are, no studies reporting on the use of HPP pre-treatment to limit the stability of the cream emulsion formed after AEE. Therefore, the main objectives of this study are to explore the effect of different HPP parameters on the stability of MO cream emulsion formed after AEE and on the total recoveries of oil. Optimization of the HPP parameters has also been undertaken to determine the most suitable conditions which result in highest MO free oil recovery.

\section{Materials and methods}

\subsection{Materials}

Mature MO seeds (PKM1 hybrid) were purchased from Genius Nature Herbs Pvt ltd., Coimbatore, India. All solvents and enzymes used in this project were obtained from Sigma-Aldrich Company Ltd., Dorset, UK. 


\subsection{Preparation of Moringa oleifera kernels for oil extraction methods}

The process flow for MO sample preparation, solvent extraction, HPP, and the AEE methods are illustrated in Fig. 1. Mat Yusoff et al. (2016) revealed that ground MO kernels of less than $710 \mu \mathrm{m}$ particle size resulted in highest hexane-extracted oil yield of $41.03 \%$ (g oil / $\mathrm{g}$ kernel), thus samples having this particle size range were used as the starting material in this study. The kernels of this particle size was prepared by grinding in a coffee grinder (De'Longhi KG49 Electric Coffee Grinder, Hampshire, UK) and sieved using a vibratory sieve shaker (Fritsch, Analysette 3E) of $710 \mu \mathrm{m}$ sieve. The solvent extraction method used is explained in section 2.5. In the HPP pre-treatment prior to the AEE, for comparison purpose, the HPP was also conducted on the MO kernels which were not ground, termed as whole kernels.

In this study, the term "oil yield" refers to the percentage of oil in the MO kernels as determined by using hexane as the extracting solvent. On the other hand, in all AEE-related processes, the term "oil released" refers to the percentage of oil extracted which includes free an emulsified oil. The "free oil recovery" refers to the percentage of oil in the top layer above the cream emulsion layer that is formed after centrifuging, the percentage being expressed relative to amount of solvent-extracted oil.

\subsection{Statistical analysis}


Minitab® 14.12.0 Statistical Software: MINITAB Release 14.12.0, New York, USA was used for all statistical analyses and determination of significant differences between the data obtained in this study. A 1-Sample t-test was applied when one datum is compared with a sample with replicates data. When two replicates were compared, a 2-Sample t-test was used, while analysis of variance (ANOVA) with Tukey's multiple comparison test was applied when more than two samples (each sample with replicates data) were involved. The confidence level used in this study was 95.0.

\subsection{High pressure processing}

The HPP parameters involved in this study were the pressure $(50-450 \mathrm{MPa})$, temperature $\left(20-60{ }^{\circ} \mathrm{C}\right)$, and processing time $(10$ $60 \mathrm{~min})$. The pressure range was determined based on earlier studies, where the amount of protein released from soybean seeds (Omi et al., 1996) and rice grains (Kato et al., 2000) increased up to $400 \mathrm{MPa}$ only, besides decrease in the amount of soybean oil extracted at $500 \mathrm{MPa}$ pre-treatment prior to an AEE method (Jung and Mahfuz, 2009). A preliminary study on the effect of HPP pre-treatment (pressure, $200 \mathrm{MPa}, 400 \mathrm{MPa}, 500 \mathrm{MPa}, 600 \mathrm{MPa} ; 25^{\circ} \mathrm{C} ; 15 \mathrm{~min}$ ) was also conducted prior to solvent extraction of $\mathrm{MO}$ oil using hexane (section 2.5). It was found that the MO oil yield was highest at $400 \mathrm{MPa}$, and slightly decreased afterwards at higher pressures (section 3.1). This finding further justified the use of lower pressure range (50-450 MPa) for the optimization purpose. In terms of the temperature range, most types of protein are fully denatured at $60{ }^{\circ} \mathrm{C}$ (Scopes, 1994) and above if held for sufficient time. In the case of the processing time, due to adiabatic temperature increase during the pressure treatment, the temperature was unstable in the first 2- 
3 min of pressurization period based on a preliminary study conducted. Therefore, a minimum of 10 min was used in order to allow enough time for the temperature to stabilize.

The statistical software (section 2.3) was used to generate the Box Behnken experimental design used in this study, where the pre-determined HPP ranges resulted in 15 design points (i.e. 15 run orders) with 3 centre points (Table 1). A mixture of MO sample and distilled water $(1: 1 \mathrm{w} / \mathrm{w}$ ratio) was transferred into a polyester bag and vacuum-sealed in order to minimize the headspace. The solid-to-liquid (MO kernel to distilled water) ratio was pre-determined based on some preliminary tests conducted. Addition of too much water resulted in a mixture which is too dilute, thus only small amount of ground MO kernels can be processed at a time. On the other hand, lower amount of water resulted in a very thick paste which adhered to the polyester bag, thus some sample is wasted. The prepared sample was further treated according to the parameters displayed in Table 1 by using a Food-Lab 900 High-Pressure Food Processor (Stansted Fluid Powder Ltd., Stansted, UK) with a mixture of 1,2-propanediol and water (70:30 v/v) as the pressure transmitting fluid.

\subsection{Solvent extraction of Moringa oleifera oil}

The total oil in MO kernel samples was determined according to the soxhlet extraction method performed by Mat Yusoff et al. (2016) using hexane as the extracting solvent in a weighed round bottom flask. In the case of solvent extraction of MO oil, it may be noted that earlier studies have conclusively shown that the use of hexane results in highest MO oil extraction while comparing hexane 
with solvents such as petroleum ether, acetone, and a mixture of chloroform and methanol (1:1) (Tsaknis et al., 1999; Mani et al., 2007). Therefore, hexane was used for the total MO oil extraction in this study. As stated in section 2.2, the particle size of the starting material was $\leq 710 \mu \mathrm{m}$. After $6 \mathrm{hr}$ of extraction time, a rotary evaporator $\left(60^{\circ} \mathrm{C}, 10 \mathrm{~min}\right)$ followed by oven drying $\left(100{ }^{\circ} \mathrm{C}, 10 \mathrm{~min}\right)$ were used to remove the hexane from the extracted MO oil. The oil yield against the weight of kernel sample used was measured as the difference between the initial weight of round bottom flask (empty) and its final weight (containing the extracted oil).

\subsection{Aqueous enzymatic extraction and determination of free oil yield and recovery}

The AEE method carried out after the HPP pre-treatment is displayed in Fig. 1(b), and the parameters used were in reference to Mat Yusoff et al. (2016). In the AEE process, centrifugation of the incubated mixture resulted in four distinct layers of free oil at the top, followed by a cream emulsion layer, an aqueous phase, and meal at the bottom. After storage for $24 \mathrm{hr}$ at $-20{ }^{\circ} \mathrm{C}$, the solidified free oil was separated into a crucible of pre-determined weight. The oil was heated in a drying oven for 15 min at $60{ }^{\circ} \mathrm{C}$ before been transferred into a desiccant containing silica gel for approximately $10 \mathrm{~min}$. These steps were conducted to ensure complete removal of aqueous phase that may still present in the separated free oil (Mat Yusoff et al., 2016). The amount of extracted oil was measured as follows: 


$$
\text { Oil yield }(\%)=\frac{[\text { Mass of crucible containing the oil }(\mathrm{g})-\text { Mass of crucible }(\mathrm{g})] \times 100}{\text { Mass of kernels initially taken }(\mathrm{g})}
$$

Free oil recovery $(\%)=\frac{\text { Mass of oil extracted from a given mass of kernel }(\mathrm{g}) \times 100}{\text { Mass of oil contained in the kernels initially taken }(\mathrm{g})}$

\section{Results and discussion}

\subsection{Effect of high pressure pre-treatment prior to solvent extraction of Moringa oleifera oil from ground-sieved kernels}

The use of solvent extraction alone on ground-sieved MO kernels of $\leq 710 \mu \mathrm{m}$ particle size resulted in $41.03 \pm 1.07 \%$ (w/w) $\mathrm{MO}$ oil yield, which was higher than the use of solvent extraction pre-treated with HPP at $200 \mathrm{MPa}, 36.75 \pm 1.89 \%$ (w/w). The oil yield however increased to $38.98 \pm 2.08 \%(\mathrm{w} / \mathrm{w})$ at $400 \mathrm{MPa}$, and slightly decreased afterwards at higher pressures of $500 \mathrm{MPa}$, $37.07 \pm 1.29 \%(\mathrm{w} / \mathrm{w})$ and at $600 \mathrm{MPa}, 36.19 \pm 2.02 \%(\mathrm{w} / \mathrm{w})$. There was no significant difference $(P>0.05)$ between the oil yields from solvent extraction alone, $41.03 \pm 1.07 \%$ (w/w), and solvent extraction with HPP pre-treatment at $400 \mathrm{MPa}, 38.98 \pm 2.08 \%$ (w/w). Approximately similar total MO oil content as extracted by hexane was also reported by Lalas and Tsaknis (2002), 38.3\% (w/w); Anwar and Bhanger (2003), 38.4\% (w/w); Ogbunugafor etal. (2011), 41.5\% (w/w); and Zhao and Zhang (2013), 40.1\% (w/w). 
Therefore, it can be concluded that the total oil content in the MO kernels used in this study was approximately $41 \%$ (w/w), and it can be achieved by using solvent extraction alone without any additional pre-treatment.

With reference to Fig. 1, the experimental procedure between the HPP and solvent extraction processes were a bit tedious due to repetition of drying, grinding and sieving steps, since solvent extraction requires dry samples. In addition, oil loss may occur along the procedures employed, and the HPP pre-treatment at all pressures tested did not increase the oil yield during the solvent extraction. Therefore, solvent extraction pre-treated with HPP was not considered as an appropriate method and was not repeated at different times and temperatures of HPP. On the other hand, an AEE requires addition of water, and the sample to be treated with high pressure needs to contain certain amount of moisture content. Thus AEE pre-treated with HPP may be more advantageous in terms of experimental procedure and oil yield. With reference to the use of solvent extraction method alone, the total oil content in MO kernels used in this study was therefore concluded to be $41.03 \pm 1.07 \%(\mathrm{w} / \mathrm{w})$, and the free oil recoveries in the following AEE experiments were calculated against this total MO oil content (section 2.6).

\subsection{Effect of high pressure pre-treatment prior to aqueous enzymatic extraction of Moringa oleifera oil from ground-sieved and whole} kernels

With reference to Fig. 2(a-b), without the HPP pre-treatment, the AEE alone resulted in $71.00 \pm 4.04 \%$ (w/w) free oil recovery with thick emulsion layer. Table 1 displays the MO free oil recoveries from AEE where the ground-sieved and whole kernels are pre- 
treated with high pressures. The highest free oil recoveries were observed in the cases of Run $15(73.02 \%$ w/w) and Run $5(57.46 \%$ w/w) for ground-sieved and whole kernels, respectively. In the case of AEE process, theoretically, the size reduction of starting materials should result in greater cell wall disruption which leads to lower diffusion path for enzymes and the cellular components, therefore resulting in higher oil yields (Mat Yusoff et al., 2015). This theory is shown to be applicable in the case of HPP processed kernels as well, where a greater amount of oil was recovered from ground-sieved kernels as compared to the whole kernels for all run orders, except runs 4 and 14. It is possible that the grinding effect of the kernels may have disrupted the protein components and increased its susceptibility to the actions of pressure, heat, and enzymes during the process. Contrary, the oil recovery for whole kernels was higher than that of ground kernels in Run 4, and in Run 14, the yields for ground and whole kernels are approximately similar - which both of these cases go against conventional wisdom. It was assumed that the use of low temperatures of $20{ }^{\circ} \mathrm{C}$ was one of the contributing factors, where the microstructure is unlikely to be disrupted for facilitating oil release. The combination of the pressurization pressure, temperature, and time in run 4 and 14 may also caused the denatured protein in ground-sieved kernels to aggregate and entrap the oil released, thus resulted in approximately similar oil recoveries with that of whole kernels. Despite these assumptions, thorough studies on the effect of HPP on the MO protein component is highly suggested.

Moreover, all AEE with HPP pre-treatments on ground-sieved kernels resulted in thinner cream emulsion layers as compared to the use of whole kernels and the use of AEE alone. These observations indicated the potential of HPP within the ranges of parameters been used in altering the MO protein structure into a form of less emulsifying functional properties, thus limiting the released oil from getting emulsified. 
3.3. Optimization of high pressure processing parameters prior to aqueous enzymatic extraction for highest Moringa oleifera free oil recovery

The sole criterion for optimization is to obtain the highest oil recovery, and the operating conditions which yield the highest recovery have been isolated on the basis of the experiments performed. No constraints - other than the reported range of the variables studied - have been considered.

Optimization was carried out for both types of starting materials to obtain the combination of HPP parameters which may result in highest MO free oil recovery. In the case of ground-sieved kernels, both, time and temperature had significant effects $(P<$ $0.05)$ on the free oil recovery, but not the pressure applied $(P>0.05)$. The linear relationship between the MO free oil recovery $(Y)$ and the significant HPP parameters $(P<0.05)$ oftime $\left(X_{1}\right)$ and temperature $\left(X_{2}\right)$ is given by: $Y=0.1287 X_{1}+0.4183 X_{2}$ with $R^{2}=0.77$. The validity of the $R^{2}$ value was confirmed from the regression $p$-value obtained which was less than 0.05 . This $p$-value indicated that the $R^{2}$ value is not meaningless or not equal to zero. Therefore, statistically, the equation can be used to estimate the changes in MO free oil recovery as a function of high pressure application time and temperature (Hair et al., 1998). The linear relationship clearly indicates that the extracted oil increased with increase in both the time and temperature in the range of parameters studied. This relationship is also graphically shown in Fig. 3, and the use of HPP for 60 min at $60{ }^{\circ} \mathrm{C}$ is predicted to result in free oil recovery of $71.43 \%(w / w)$, regardless of the pressure applied. Additionally, there was no interaction effect $(P>0.05)$ between the HPP parameters 
used. In contrast to ground-sieved kernels, none of the HPP parameters significantly influenced free oil recovery $(P>0.05)$ from whole kernels. Therefore, further experiments in this study focused on the ground-sieved kernels as the starting material.

Based on the experiments conducted with ground-sieved kernels (Table 1), Run 15 at $50 \mathrm{MPa}\left(60{ }^{\circ} \mathrm{C}, 35\right.$ min) resulted in higher free oil recovery of $73.02 \%(w / w)$ as compared to Run 6 at higher pressure of $450 \mathrm{MPa}\left(60{ }^{\circ} \mathrm{C}, 35\right.$ min) which yielded $66.15 \%$ (w/w) oil. Run 15 also yielded highest free oil recovery than that of other run orders. Therefore, an additional experiment was carried out at similar pressure of $50 \mathrm{MPa}$ in combination with the optimized parameters $\left(60 \mathrm{~min}, 60^{\circ} \mathrm{C}\right)$, and this resulted in significantly lower $(P<0.05)$ free oil recovery of $65.91 \pm 1.76 \%(\mathrm{w} / \mathrm{w})$ as compared to Run 15 , despite the longer pressurization time. This free oil recovery was also significantly lower $(P<0.05)$ than the value of $71.43 \%(\mathrm{w} / \mathrm{w})$ predicted in the experimental design. According to Anglemier and Montgomery (1976), denaturation of native protein occurs under heat or pressure, but there is also a possibility for the denaturation to be reversible when the proteins are smaller and/or the denaturing conditions are milder. On the other hand, there is also a possibility for the protein to aggregate after applying high pressures for a given time, which can re-emulsify the oil released and therefore decrease the free oil recovery. Therefore, due to significantly higher $(P<0.05)$ free oil recovery at shorter pressurization time of 35 min, Run 15 was more acceptable as compared to the optimized HPP parameters and was further been used in this study.

\subsection{Effect of boiling and high pressure pre-treatments prior to aqueous enzymatic extraction of Moringa oleifera oil}


In section 3.2-3.3, it was revealed that the HPP pre-treatment on ground-sieved MO kernels prior to the AEE did not significantly enhance the MO free oil recovery, yet thinner cream emulsion layer was formed as compared to the AEE alone. This finding indicates the potential of HPP in altering the MO protein structure into a form which exhibits less emulsifying functional properties, thus minimizing the amount of cream emulsion formed and further reducing the load of de-emulsification step. Despite this advantage, the total oil released from the MO kernels may be lower with the use of HPP pre-treatment due to the thinner cream emulsion layer which indicates smaller amount of emulsified oil. Additionally, with reference to Fig. 1(b), the AEE itself was preceded with a gentle boiling step on the moisture/kernel mixture for 5 min prior to adjusting the mixture's pH. Adding an HPP pretreatment prior to the gentle boiling step may not be of great advantage particularly in terms of the overall processing cost and the workload. Therefore, additional experiments were carried out to observe the effect of replacing the gentle boiling step with the HPP pre-treatment. For this purpose, the boiling step was termed as boiling pre-treatment, and the AEE itself was carried out without the gentle boiling step and termed as AE** to avoid confusion. These new experimental procedures are summarized in Fig. 4 for better understanding. In the following experiments, the AEE* with boiling pre-treatment is termed as B-AEE*, while the AEE* with HPP pre-treatment is termed as HPP-AEE*.

With reference to Fig. 5, there was no significant difference $(P>0.05)$ between the free oil recoveries from AEE*, B-AEE*, and HPP-AEE* methods, yet the HPP-AEE* resulted in thinner cream emulsion layer as compared to the other processes. Despite the insignificant difference in the free oil recoveries, the B-AEE* resulted in $4.98 \%$ higher free oil recovery than the AEE* alone. In both of these cases, it was assumed that higher amount of oil was released from the MO kernels, yet certain amount of the released oil was 
emulsified into thick cream emulsion layer. On the other hand, HPP-AEE* resulted in $4.19 \%$ higher free oil recovery than that of AEE* alone. The higher free oil recovery may be due to the effect of HPP in altering the MO protein structure into a form of less emulsifying ability, thus preventing the released oil from getting emulsified and resulted in thin cream emulsion layer. Similar finding was reported in the case of Vicia faba, where its $11 \mathrm{~S}$ proteins exhibited poor emulsifying properties upon HPP treatment (Galazka et al., 2000). However, Chapleau and de Lamballerie-Anton (2003a) reported contrast result, where the emulsifying properties of lupin proteins improved upon HPP at $400 \mathrm{MPa}$.

These findings proved that combination of different running time, temperature, and pressure in the HPP resulted in different free oil recoveries and cream emulsions which is very much dependent on changes in the protein structure. Similar types of protein molecules display varying structural differences or microstates upon exposure to the same denaturation treatment. Additionally, native proteins require very high activation energy for denaturation to take place (Anglemier and Montgomery, 1976). These changes in the protein structure may increase its susceptibility for enzymatic hydrolysis, or may increase its efficiency as an emulsifier. Both of these situations may also occur simultaneously, or vice versa.

\section{Conclusion}

HPP pre-treatment $\left(25^{\circ} \mathrm{C}, 15 \mathrm{~min}, 200-600 \mathrm{MPa}\right)$ prior to solvent extraction did not significantly increase the MO oil yield from ground kernels at all the pressures tested. However, when HPP was used prior to aqueous enzymatic extraction, greater yields 
were obtained with ground kernels than whole kernels under otherwise similar extraction conditions. Further, the emulsion layers formed with ground kernels were thinner than those formed with whole kernels. In general the emulsion layers formed by employing HPP pre-treatment were thinner than one formed without the use of HPP. The highest free oil was recovered in Run 15 (73.02\% w/w) and Run $5(57.46 \%$ w/w) for the ground-sieved kernels and whole kernels, respectively. The optimization of the HPP parameters revealed that free oil recovery increased significantly $(P<0.05)$ with increase in temperature and extraction time, but not with the pressure level applied. Run $15\left(50 \mathrm{MPa}, 60^{\circ} \mathrm{C}, 35 \mathrm{~min}\right)$ resulted in significantly higher $(P<0.05)$ free oil recovery $(73 \%(\mathrm{w} / \mathrm{w}))$ than the optimized HPP parameters $\left(50 \mathrm{MPa}, 60^{\circ} \mathrm{C}, 60 \mathrm{~min}, 65 \% \mathrm{w} / \mathrm{w}\right)$, possibly due to reversible denaturation or aggregation of proteins under prolonged pressure application. Additional experiments were conducted on the mixture of moisture/kernel samples treated with AEE without the pre-boiling step (termed as AEE*), with the pre-boiling step (termed as B-AEE*), and with the HPP pre-treatment (HPP-AEE*). Both the B-AEE* and $\mathrm{HPP}-\mathrm{AEE}^{*}$ resulted in $4.98 \%$ and $4.19 \%$ higher free oil recoveries than that of AEE* alone, respectively, yet the differences were statistically insignificant $(P>0.05)$, and the HPP-AEE* resulted in thinner cream emulsion layer than that of other processes. It was assumed that greater amount of oil was released from the MO kernels in the case of AEE* and B$\mathrm{AEE}^{*}$, but part of the released oil got emulsified. In the case of HPP-AEE*, the higher free oil recovery as compared to that of AEE* may be due to the effect of HPP in altering the MO protein structure into a form of less emulsifying ability, thus preventing the released oil from getting emulsified. The load of de-emulsification method afterwards can therefore be minimized, or may not be necessary at all. Despite these findings, the free oil recoveries were still lower than that of solvent extraction method. Further studies are recommended on the quality attributes of MO oils from solvent and AEE methods of different pre-treatments. 


\section{Acknowledgement}

The authors gratefully acknowledge the Ministry of Higher Education (MOHE) in Malaysia for supporting the doctoral grant, and to the Universiti Putra Malaysia, UPM Serdang, Malaysia for giving permission to one of the authors (Masni Mat Yusoff) to study in the University of Reading, Reading, UK.

\section{References}

Abdulkarim, S. M., Long, K., Lai, O. M., Muhammad, S. K. S., \& Ghazali H. M. (2005). Some physico-chemical properties of Moringa oleifera seed oil extracted using solvent and aqueous enzymatic methods. Food Chemistry, 93, 253-263.

Abdulkarim, S. M., Lai, O. M., Muhammad, S. K. S., Long, K., \& Ghazali, H. M. (2006). Use of enzymes to enhance oil recovery during aqueous extraction of Moringa oleifera seed oil. Journal of Food Lipids, 13, 113-130.

Anglemier, A. F., \& Montgomery, M. W. (1976). Amino acids, peptides, and proteins. In O. R. Fennema (Ed.), Principles of Food Science. Part 1: Food Chemistry (pp. 205-278). New York: Marcel Dekker Inc.

Anwar, F., \& Bhanger, M. I. (2003). Analytical characterization of Moringa oleifera seed oil grown in temperate regions of Pakistan. Journal of Agricultural and Food Chemistry, 51, 6558-6563.

Chapleau, N. J., \& de Lamballerie-Anton, M. (2003). Changes in myofibrillar proteins interactions and rheological properties induced by high pressure processing. European Food Research and Technology, 216(6), 470-476. 
Chapleau, N. J, \& de Lamballerie-Anton, M. (2003a). Improvement of emulsifying properties of lupin proteins by high pressure induced aggregation. Food Hydrocolloids, 17, 273-280.

Denda, A., \& Hayashi, R. (1992). Emulsifying properties of pressure treated proteins. In C. Balny, R. Hayashi, K. Heremans, \& P. Masson (Eds.), High Pressure and Biotechnology (Vol. 224, pp. 333-335). Colloque INSERM/John Libbey Eurotext Ltd.

Ezeh, O., Gordon, M. H., \& Niranjan, K. (2016). Enhancing the recovery of tiger nut (Cyperus esculentus) oil by mechanical pressing: Moisture content, particle size, high pressure and enzymatic pre-treatment effects. Food Chemistry, 194, 354-361.

Gai, Q. Y., Jiao, J., Mu, P. S., Wang, W., Luo, M., Li, C. Y., Zu, Y. G., Wei, F. Y., \& Fu, Y. J. (2013). Microwave-assisted aqueous enzymatic extraction of oil from Isatis indigotica seeds and its evaluation of physicochemical properties, fatty acid compositions and antioxidant activities. Industrial Crops and Products, 45, 303-311.

Galazka, V. B., Dickinson, E., \& Ledward, D. A. (2000). Influence of high pressure on interactions of 11S globulin Vicia faba with icarrageenan in bulk solution and at interfaces. Food Hydrocolloids, 14, 551-560.

Hair, J. F., Anderson, R. E., Tatham, R. L., \& Black, W. C. (1998). Multiple regression analysis. In J. F. Hair, R. E. Anderson, R. L. Tatham, \& W. C. Black (Eds.), Multivariate data analysis (pp. 141-216). New Jersey: Prentice-Hall Inc.

Jung, S., \& Mahfuz, A. A. (2009). Low temperature dry extrusion and high-pressure processing prior to enzyme-assisted aqueous extraction of full fat soybean flakes. Food Chemistry, 114, 947-954.

Kajiyama, N., Isobe, S., Uemura, K., \& Noguchi, A. (1995). Changes of soy protein under ultra-high hydraulic pressure. International Journal of Food Science and Technology, 30, 147-158.

Kato, T., Katayama, E., Matsubara, S., Omi, Y., \& Matsuda, T. (2000). Release of allergenic proteins from rice grains induced by high hydrostatic pressure. Journal of Agricultural and Food Chemistry, 48(8), 3124-3129.

Lalas, S., \& Tsaknis, J. (2002). Characterization of Moringa oleifera seed oil variety "Periyakulum 1". Journal of Food Composition and Analysis, 15, 65-77.

Lamsal, B. P., \& Johnson, L. A. (2007). Separating oil from aqueous extraction fractions of soybean. Journal of the American Oil Chemists' Society, 84, 785-792. 
Latif, S., Anwar, F., Hussain, A. I., \& Shahid, M. (2011). Aqueous enzymatic process for oil and protein extraction from Moringa oleifera seed. European Journal of Lipid Science and Technology, 113, 1012-1018.

Mani, S., Jaya, S., \& Vadivambal, R. (2007). Optimization of solvent extraction of Moringa (Moringa oleifera) seed kernel oil using response surface methodology. Food and Bioproducts Processing, 85(C4), 328-335.

Mat Yusoff, M., Gordon, M. H., \& Niranjan, K. (2015). Aqueous enzyme assisted oil extraction from oilseeds and emulsion deemulsifying methods: A review. Trends in Food Science and Technology, 41, 60-82.

Mat Yusoff, M., Gordon, M. H., \& Niranjan, K. (2016). Aqueous enzymatic extraction of Moringa oleifera oil. Food Chemistry, 211, 400-408.

Messens, W., Van Camp, J., \& Huyghebaert, A. (1997). The use of high pressure to modify the functionality of food proteins. Trends in Food Science and Technology, 8, 107-112.

Molina, E., Papadopoulou, A., \& Ledward, D. A. (2001). Emulsifying properties of high pressure treated soy protein isolate and 7S and 11S globulins. Food Hydrocolloids, 15, 263-269.

Nguyen, H. N., Gaspillo, P. D., Maridable, J. B., Malaluan, R. M., Hinode, H., Salim, C., \& Huynh, Ha K. P. (2011). Extraction of oil from Moringa oleifera kernels using supercritical carbon dioxide with ethanol for pre-treatment: Optimization of the extraction process. Chemical Engineering and Processing, 50, 1207-1213.

Noakes, M., Nestel, P. J., \& Clifton, P. M. (1996). Commercial frying fats and plasma lipid-lowering potential. Australian Journal of Nutrition and Dietics, 53(1), 25-30.

Ogbunugafor, H. A., Eneh, F. U., Ozumba, A. N., Igwo-Ezikpe, M. N., Okpuzor, J., Igwilo, I. O., Adenekan, S. O., \& Onyekwelu, O. A. (2011). Physico-chemical and antioxidant properties of Moringa oleifera seed oil. Pakistan Journal of Nutrition, 10(5), 409414.

Omi, Y., Kato, T., Ishida, K., Kato, H., \& Matsuda, T. (1996). Pressure-induced release of basic 7S globulin from cotyledon dermal tissue of soybean seeds. Journal of Agricultural and Food Chemistry, 44, 3763-3767. 
Parker, M. L., Ng, A., Smith, A. C., \& Waldron, K. W. (2000). Esterified phenolics of the cell walls of chufa (Cyperus esculentus L.) tubers and their role in texture. Journal of Agricultural and Food Chemistry, 48(12), 6284-6291.

Rahman, I. M. M., Barua, S., Nazimuddin, M., Begum, Z. A., Azizur Rahman, M., \& Hasegawa, H. (2009). Physicochemical properties of Moringa oleifera Lam. seed oil of the indigenous-cultivar of Bangladesh. Journal of Food Lipids, 16, $540-553$.

Rosenthal, A., Pyle, D. L., \& Niranjan, K. (1996). Aqueous and enzymatic processes for edible oil extraction. Enzyme and Microbial Technology, 19, 402-420.

Rosenthal, A., Pyle, D. L., \& Niranjan, K. (1998). Simultaneous aqueous extraction of oil and protein from soybean: mechanisms for process design. Transactions of IChemE, 76, 224-230.

Scopes, R. K. (1994). Separation by precipitation. In R. K. Scopes (Ed.), Protein Purification: Principles and Practice (3rd ed.). New York: Springer Science+Business Media.

Tsaknis, J., Lalas, S., Gergis, V., Dourtoglou, V., \& Spiliotis, V. (1999). Characterization of Moringa oleifera variety Mbololo seed oil of Kenya. Journal of Agricultural and Food Chemistry, 47, 4495-4499.

Zhang, Y. L., Li, S., Yin, C. P., Jiang, D. H., Yan, F. F., \& Xu, T. (2012). Response surface optimisation of aqueous enzymatic oil extraction from bayberry (Myrica rubra) kernels. Food Chemistry, 135, 304-308.

Zhao, S., \& Zhang, D. (2013). A parametric study of supercritical carbon dioxide extraction of oil from Moringa oleifera seeds using a response surface methodology. Separation and Purification Technology, 113, 9-17.

\section{Title of figures}

Fig. 1. (a) Process flow of preparation of Moringa oleifera kernels for high pressure processing (HPP) pre-treatment prior to solvent extraction and aqueous enzymatic extraction (AEE) methods. 15 run orders; the 15 different HPP parameters conducted on groundsieved $^{\mathrm{a}}$ and whole ${ }^{\mathrm{b}}$ kernels (Refer Table 1). (b) The AEE method conducted following the HPP pre-treatment. 
Fig. 2. The Moringa oleifera (a) oil recovery and (b) nature of cream emulsion formed from aqueous enzymatic extraction (AEE) method, and from AEE with high pressure processing (HPP) pre-treatment. GS, ground-sieved. Oil recoveries followed by the different letters are significantly different $(P<0.05)$.

Fig. 3. The linear relationship between the high pressure processing (HPP) temperature and time in affecting the Moringa oleifera oil recoveries as a pre-treatment prior to aqueous enzymatic extraction method, generated by Minitab® 14.12.0 Statistical Software: MINITAB Release 14.12.0, New York, USA.

Fig. 4. The new experimental procedure to determine the effect of boiling and high pressure processing pre-treatments prior to the aqueous enzymatic extraction (AEE*) method. The AEE* with boiling pre-treatment is termed as B-AEE*, while the AEE* with high pressure processing pre-treatment is termed as HPP-AEE*.

Fig. 5. The Moringa oleifera (a) oil recovery and (b) nature of cream emulsion formed from aqueous enzymatic extraction (AEE*) method, and from AEE* with boiling (B-AEE*) and high pressure processing (HPP-AEE*) pre-treatment, with ground-sieved kernels as starting material. Oil recoveries followed by the same letter are not significantly different $(P>0.05)$. 
Table 1.

High pressure processing (HPP) parameters as obtained from Box-Behnken design (MINITAB ${ }^{\text {TM }}$ Statistical Software: MINITAB Release 14.12.0, New York, USA), based on the pre-determined range of each parameter. Each HPP run order is carried out on whole and ground-sieved Moringa oleifera kernels, followed by an aqueous enzymatic extraction method (4:1 moisture/kernel $(\mathrm{w} / \mathrm{w})$ ratio at $\mathrm{pH} 6.0$, incubated at $50{ }^{\circ} \mathrm{C}$ for $12.5 \mathrm{hr}$ at 300 stroke/min shaking speed)

\begin{tabular}{llllll}
\hline Run order & Pressure & $\begin{array}{l}\text { Temperature } \\
\left(20-60^{\circ} \mathrm{C}\right)\end{array}$ & $\begin{array}{l}\text { Time } \\
(10-60 \mathrm{~min})\end{array}$ & Free oil recovery $(\% \mathrm{w} / \mathrm{w})$ \\
& $(50-450 \mathrm{MPa})$ & & & $\begin{array}{l}\text { Whole } \\
\text { kernels }\end{array}$ & $\begin{array}{l}\text { Ground- } \\
\text { sieved kernels }\end{array}$ \\
& & & & 41.47 & 54.09 \\
\hline 1 & 250 & 20 & 60 & 45.62 & 57.33 \\
2 & 250 & 40 & 35 & 55.68 & 64.35 \\
3 & 250 & 60 & 10 & 51.53 & 47.23 \\
4 & 450 & 20 & 35 & 57.46 & 58.43 \\
5 & 450 & 40 & 10 & 46.19 & 66.15 \\
6 & 450 & 60 & 35 & 47.60 & 57.33 \\
7 & 250 & 40 & 35 & 52.59 & 68.34 \\
8 & 50 & 40 & 60 & 51.11 & 58.68 \\
9 & 50 & 40 & 10 & 47.17 & 50.04 \\
\hline 10 & 50 & 20 & & & \\
\hline
\end{tabular}




\begin{tabular}{llllll}
\hline 11 & 250 & 40 & 35 & 49.91 & 57.49 \\
12 & 250 & 60 & 60 & 52.51 & 64.95 \\
13 & 450 & 40 & 60 & 46.03 & 70.01 \\
14 & 250 & 20 & 10 & 50.29 & 50.17 \\
15 & 50 & 60 & 35 & 54.12 & 73.02 \\
\hline
\end{tabular}


Mature Moringa oleifera seeds

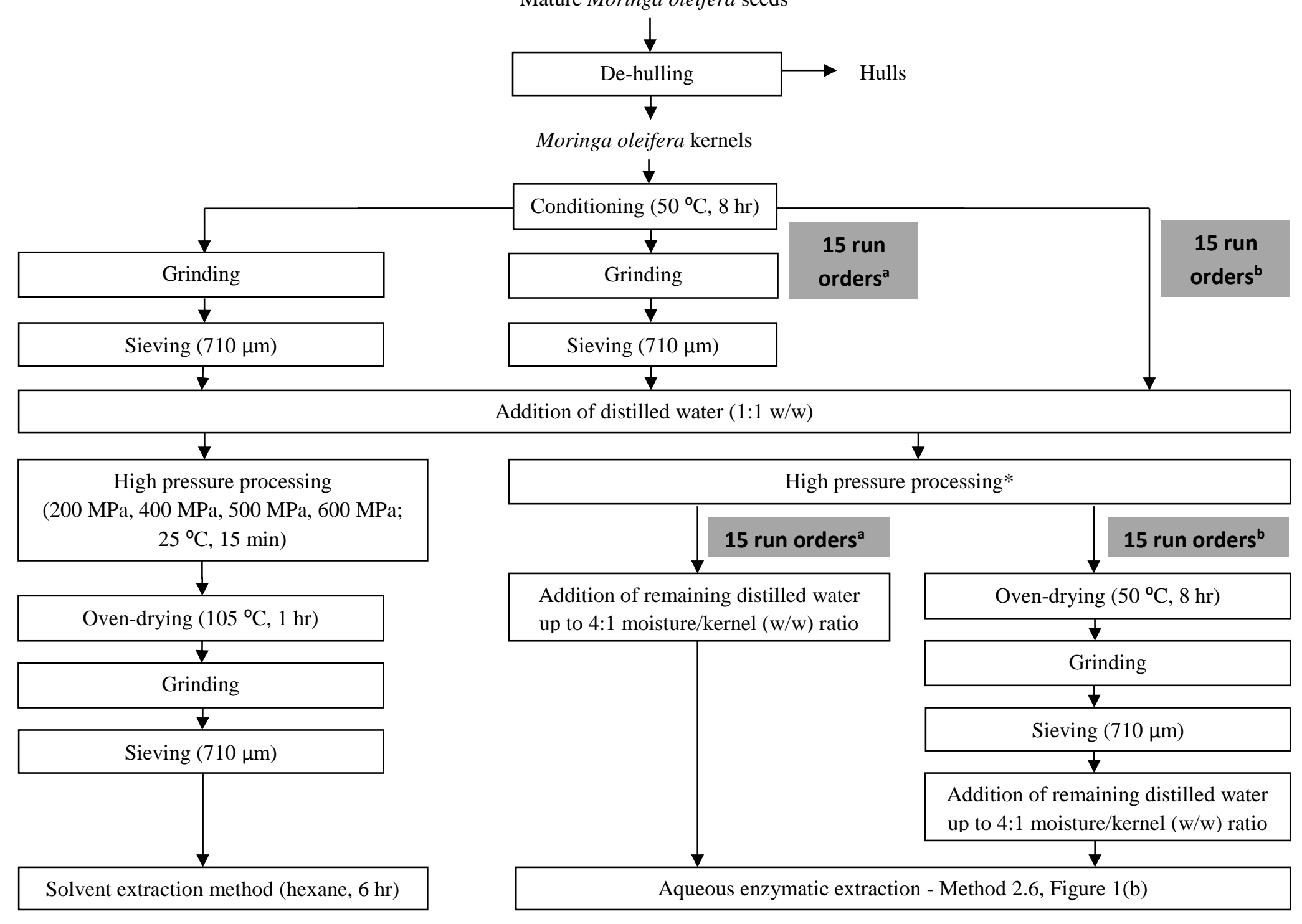

Fig. 1(a) 
1

2

3

4

5

6

7

8

9

10

11

12

13

14

15

16

17

18

19

20

21

22

23

24

25

26

27

28

Fig. 1(b)

Gentle boiling of the mixture ( $5 \mathrm{~min}$ )

Cooling the mixture to room temperature

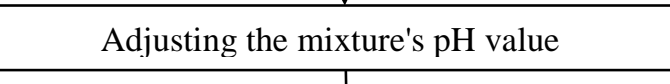

Addition of 2\% (w/w) enzyme mixture of

Neutrase $0.8 \mathrm{~L}$ and Celluclast $1.5 \mathrm{~L}$ at $3: 1$ ratio

Incubation of the mixtures at $50{ }^{\circ} \mathrm{C}$ for 12.5

$\mathrm{hr}$ at 300 stroke/min shaking speed

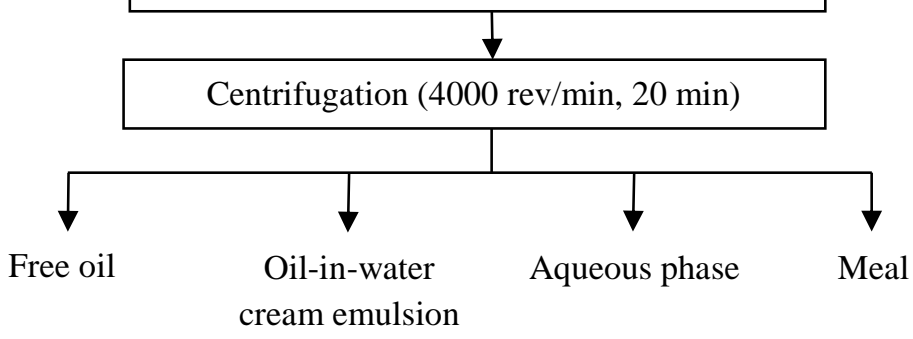




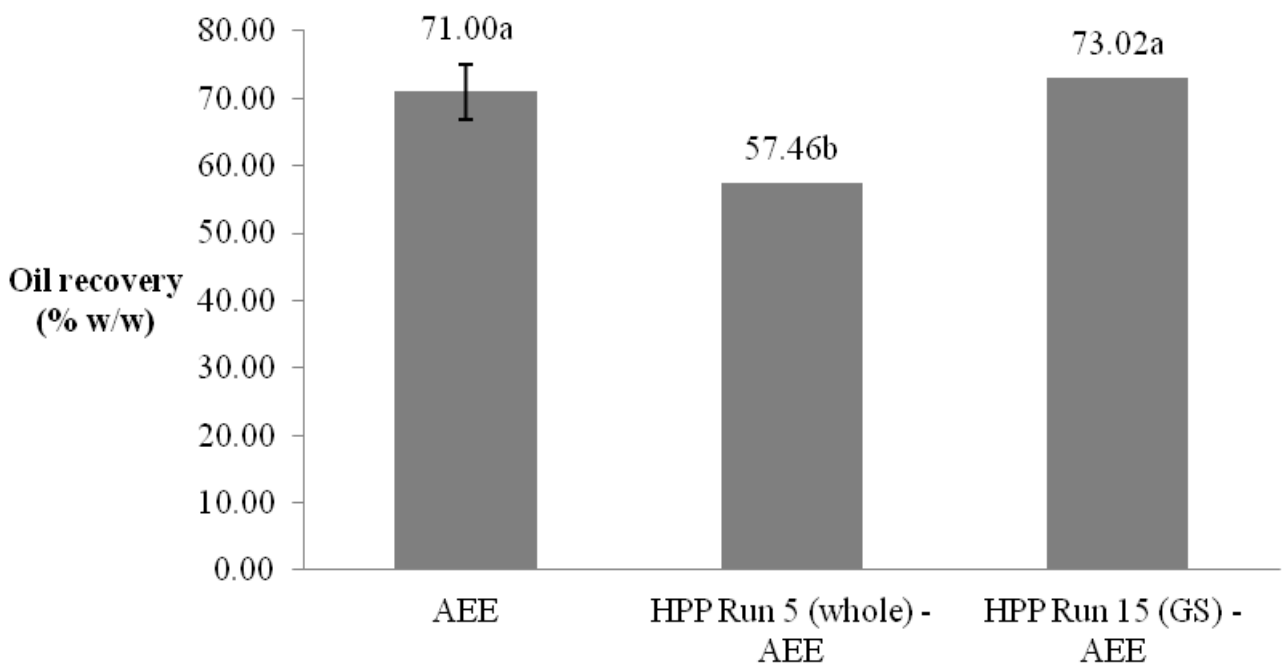

Fig. 2(a)

31

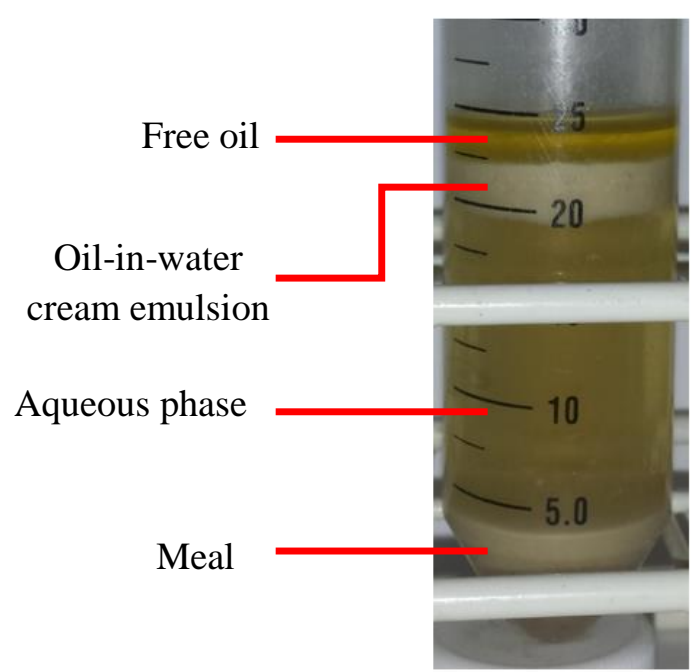

AEE

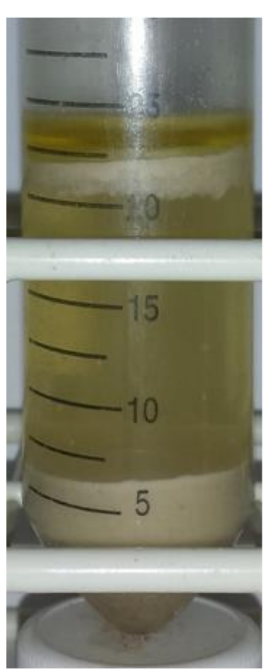

Wholekernels: Ground-sieved HPP Run 5 AEE

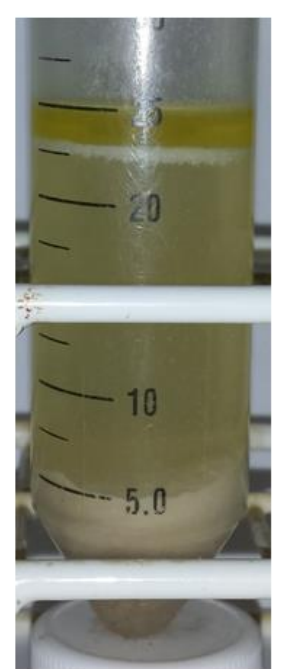

kernels: HPP Run 15 AEE

Fig. 2(b) 

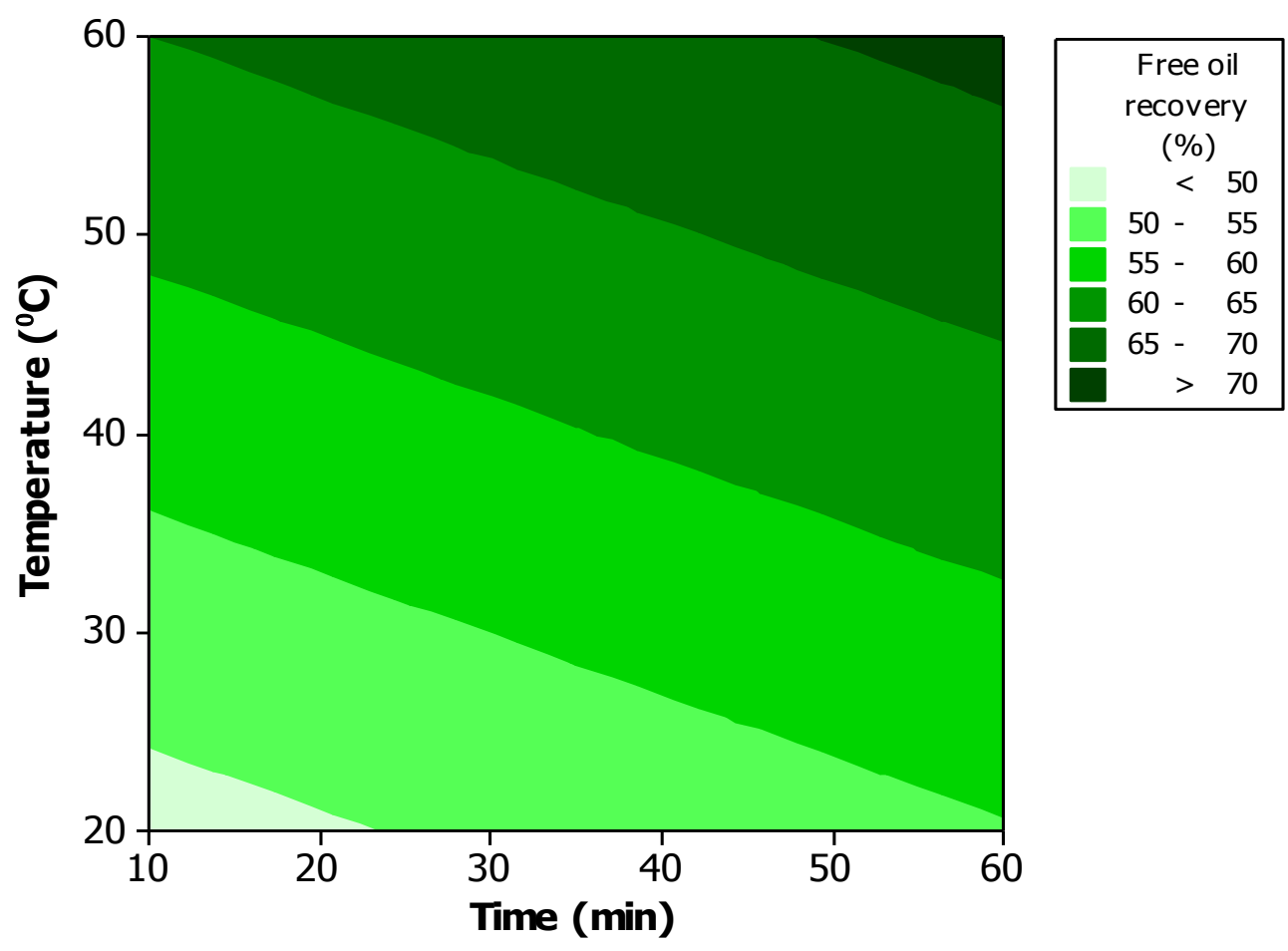

38

39

40

Fig. 3

41

42

43

44

45

46

47

48

49

50

51

52 
Adjusting the mixture's $\mathrm{pH}$ value

Addition of $2 \%(\mathrm{w} / \mathrm{w})$ enzyme mixture of Neutrase $0.8 \mathrm{~L}$ and Celluclast $1.5 \mathrm{~L}$ at $3: 1$ ratio

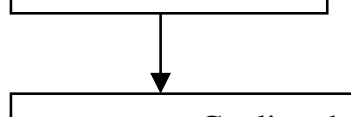

Cooling the mixture to room temperature

High pressure processing (HPP) pre-treatment (50 $\left.\mathrm{MPa}, 60^{\circ} \mathrm{C}, 35 \mathrm{~min}\right)$
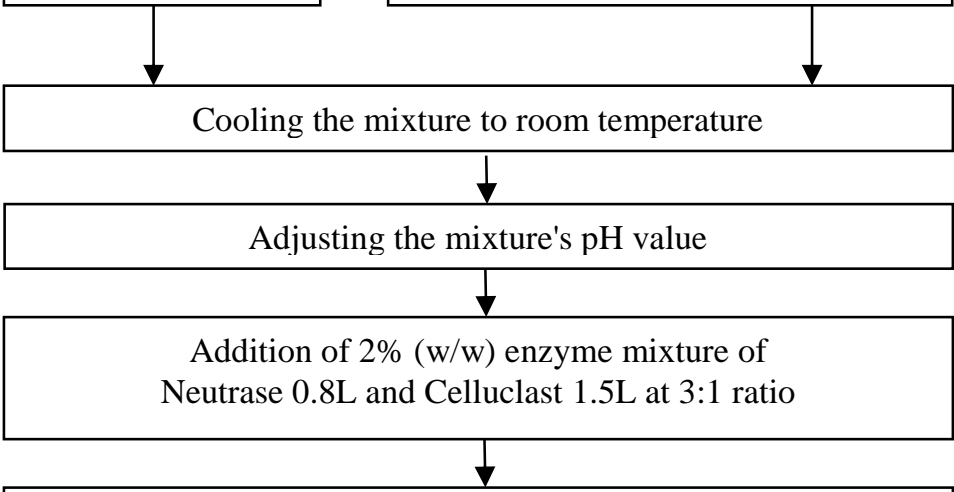

Incubation of the mixtures at $50{ }^{\circ} \mathrm{C}$ for $12.5 \mathrm{hr}$ at 300 stroke/min shaking speed

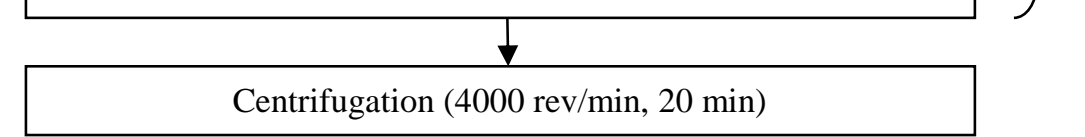

Aqueous enzymatic extraction (AEE*) 


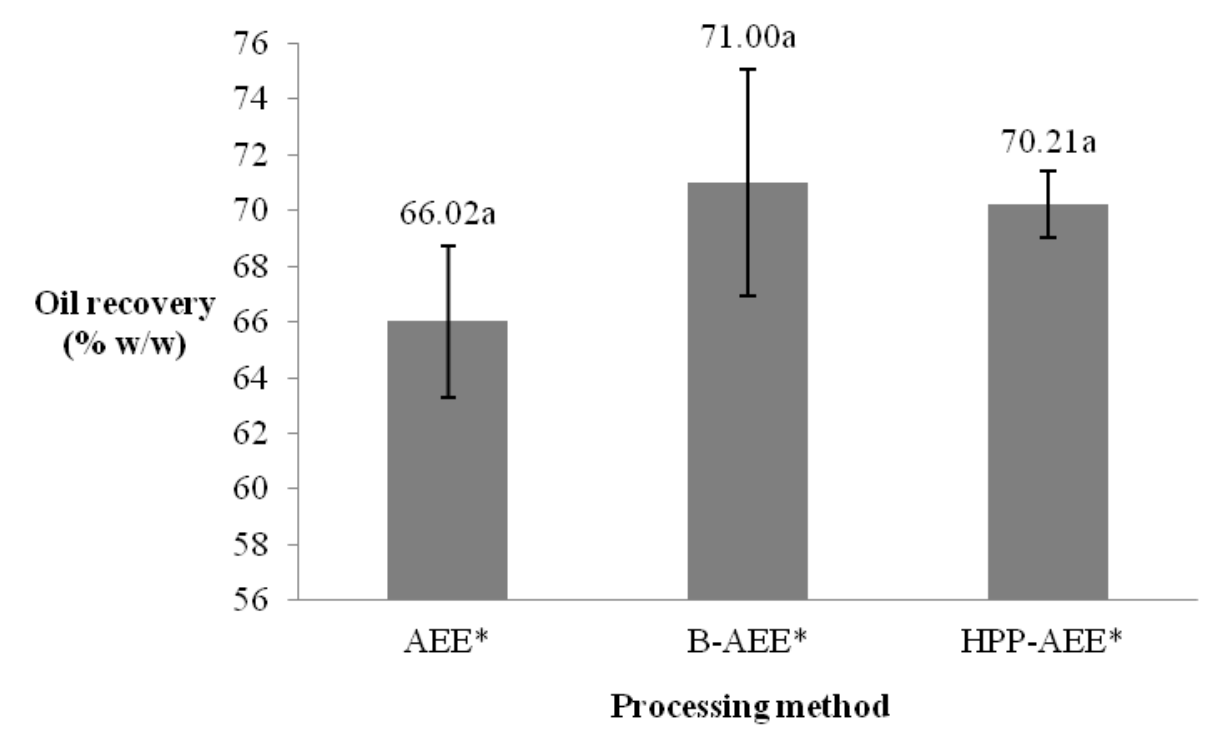

Fig. 5(a)

79

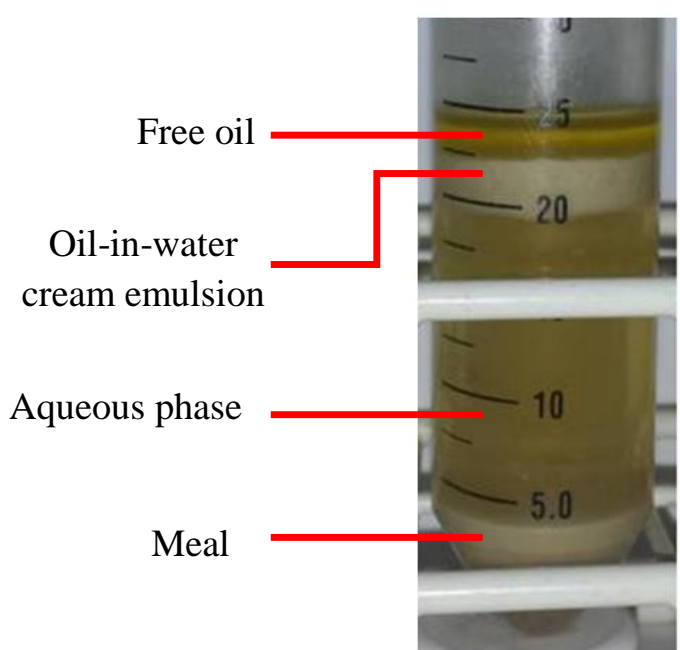

AEE*
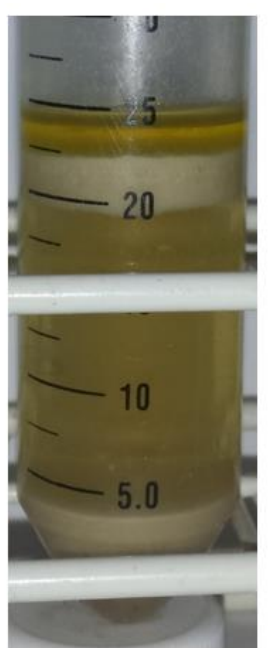

B-AEE*
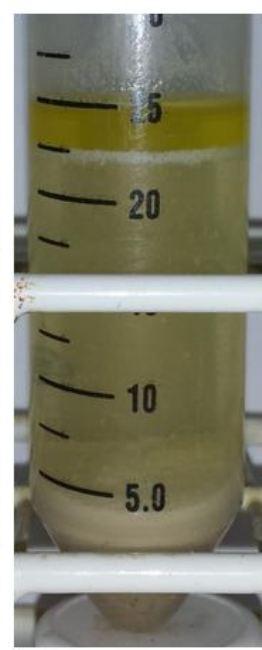

HPP-AEE*

Fig. 5(b) 